\title{
Drugs Relationship Discovery using Hypergraph
}

\author{
Shalini R \\ National Institute of Technology, Tiruchirapalli, \\ Department of Computer Science and Engineering, Tiruchirapalli, 620015, India \\ E-mail: $406916001 @$ nitt.edu \\ Mohan R \\ National Institute of Technology, Tiruchirapalli \\ Department of Computer Science and Engineering, Tiruchirapalli, 620015, India \\ E-mail: rmohan@nitt.edu
}

Received: 26 December 2017; Accepted: 07 May 2018; Published: 08 June 2018

\begin{abstract}
Globally, the governments are concerned for saving human life but in recent days, the cost of medicine to save the human life grows rapidly, due to the different combination of the drugs sold by the drug store and based on the drugs availability in the drug store. As a regular routine, the Clinical physicians prescribe the drug name or druggist company name for the patient, instead of prescribing the brand name. For a particular drug name, more number of brand name both generic drugs and combination drugs were available. Almost all the physicians or druggist knows these generic drugs and combination drugs along with their dosage and recommends it for the patient. Since the patients are unaware about the brand name of the medicine, they are buying the costly drug without knowledge. At the same time the patients whoever provide the review on the drug consumed, mostly gives a negative review. On the other side, Government gives approval for every drug produced year by year and those drugs getting rejected for approval where sent for new alternative extension of chemical formula, as well government bans several combinations of drugs. There should be a database for awareness; it should help physicians, druggist and end user to look for banned and unbanned drug. We have identified that the drug details and their approvals were not maintained in the database. So, the proposed work is (i) to identify and classify the exact drug, which can be used as generic or combination and (ii) to create a banned drug model representation, which was unavailable.
\end{abstract}

A hypergraph-based model named Drugs Relationship Discovery using Hypergraph (DRDH) was constructed as a preliminary design representation for drugs. Here, the drugs combination was considered as a hypervertex and the combination approved for manufacturing in the particular company was considered as an edge, having weight as the price of single dose usage based on Indian government listed drug. With this proposed model as a reference, the banned drugs are listed separately, manufacturing stopped drugs are highlighted with the weight of -1 and the physician or druggist can access the model to ensure the correct drug, their production, and usage. The Time complexity has been analyzed for the hypergraph, which was constructed based on the details of relationship identified among the drugs. Using the parameters of the list of drugs used in India on fever and the common cold, comparison over time taken to identify the relationship has also been done.

Index Terms-Hypergraph, banned drugs, generic drugs, database, data modeling, drug relationship.

\section{INTRODUCTION}

Health care is developing progressively more complex, and new methods to diagnosis and for treatment are focused in most of the clinical research. Few methods are comparatively targeted to the perfection of operational systems with effort, which is partially responsible for the medical safety-related problems. Doctors and public health experts in India and abroad have reported that increasing use of antibiotic mixtures in India may be funding for antibiotic resistance.

India is bigger than any country in the world in market share for the combination drugs versus single drugs. Before the announcement to market, the drugs need to undergo rigorous testing. Clinical trials made on the drugs for their safety and its efficacy are also analyzed by testing first on animals and then on human beings.

Despite all precautions, some adverse effects of drugs are noticed only when the drug is used in the overall density of population after its approval. While such drugs are unlawful to hold, many of the governments normalize the sale and use certain drugs, manufacturing, marketing, distributing, for example over a prescription method.

For instance, amphetamines (the addictive drugs) might be lawful to have it, if a doctor prescription is made; otherwise, ownership or sale of drug is naturally a criminal offense. Combination drugs are used globally to improve patient's amenability, as it is easier to get patients to take one drug rather than numerous. By unpredictable examination of the drug by the law in India that led to discharges of hundreds of new medicines come to the market for approval from regulators of different states, apart from the central government.

In 2014, India a group committee appraised more than 
6,000 blends that had come in the market established only on state regulators' approval. Policymakers provided pharmaceutical companies accidental to retroactively substantiate the safety and worth of these drugs by succumbing data on their drugs. If medicine is to accomplish major gains in excellence, it must be transformed, and information technology will play a significant part, specifically with esteem to safety.

Hypergraph take an extensive view of standard graphs by describing edges among multiple vertices in its place of only two vertices. Hence some properties must be a generality of graph properties. Hypergraph can be observed as incidence structures. Hypergraph have a lot of other names. In computational geometry, a hypergraph might be called as a range space, and then the hyperedges are also called as ranges. In cooperative game theory, hypergraph is also called as simple games (voting games); this idea is useful to a resolution to the problems in social choice theory. Distinct varieties of hypergraph include kuniform ones, misperceptions, where no edge look as if a subset of another edge; and abstract simplified complexes, which grip all subsets of every edge.

This paper is organized as follows. The next section presents the related work for the relational representation of hypergraph and government ban on drugs. Section III develops a Drugs Relationship Discovery algorithm for the random walk computation. Section IV identifies relationship among the drugs, discusses about the construction of hypergraph for a sample dataset and evaluates the time taken to construct the hypergraph. Conclusions and Future Work are presented in Section V.

\section{RELATED WORKS}

\section{A. Hypergraph for Relational Representation}

Hypergraph specify the collective idea of graphs by reassuring the portrayal of edges. An edge in a graph is merely a duo of vertices. As a substitute, a hyperedge in a hypergraph is a group of vertices. In clustering of vertices that can be structured and subsequently, some additional restrictions intricate in different possible definitions of hypergraph.

The hypergraph and its structure can be derivative from the three basic premises:

1. A hypergraph comprises of a non-empty set of hyperedges and a set of vertices.

2. A hyperedge is a limited set of vertices (different by specific roles they perform in that hyperedge).

3. A hyperedge is also a vertex and it can be linked by other hyperedges.

The relational model is the most generally used data model for storing the huge datasets, per chance due to the effortlessness of the tabular format which had transfigured database management systems. However, many real-world objects are recursive and associative in nature which creates storage in the relational model difficult. $[1,15]$
From the Fig. 1, an instance of a nearly block-diagonal matrix and its equivalent hypergraph is shown. Each row of the matrix relates to a hyperedge, and each column relates to vertices $v 1$ through $v 8$. Iteratively bisecting the graph line up the blocks of the matrix on the diagonal. [14]

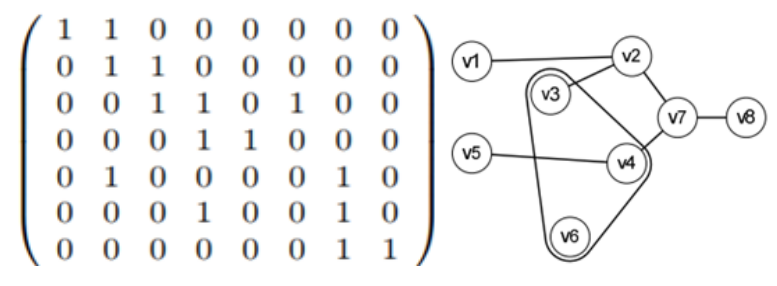

Fig.1. Relationship Matrix- Hypergraph

A hypergraph with a family $E$ of a discrete subsets of a determinate set $\mathrm{V}$, is represented as $\mathrm{H}=(\mathrm{V}, \mathrm{E})$. The memberships of $\mathrm{E}$ are called hyperedges, and the elements of $\mathrm{V}$ are named as vertices. Searching for comparable data models in a given database basically relates to the fundamental problematic of nearest neighbor search. Thoroughly correlating a query point $\mathrm{q}$ with each sample in a database $\mathrm{X}$ is infeasible because the linear time complexity $\mathrm{O}(|\mathrm{X}|)$ tends to be exclusive in realistic large-scale settings. The large-scale application is most practical and suffer more from the curse of dimensionality due to scalability issue, since data below the modern analytics it contains thousands or even tens of thousands of dimensions, for instance, in documents and images. [2, 6]

Author [21] says each image can be represented by combination of the several visual concepts. Visual concept is the specific object or part of an image. There are several images in the database which can share multiple visual concepts. To capture such a relationship between group of images hypergraph is used. In the work, each image is considered as a vertex and each visual concept as a hyperedge in a hypergraph. All the images sharing same visual concept, form a hyperedge. Images in the dataset are represented using hypergraph. For each query image visual concept is identified.

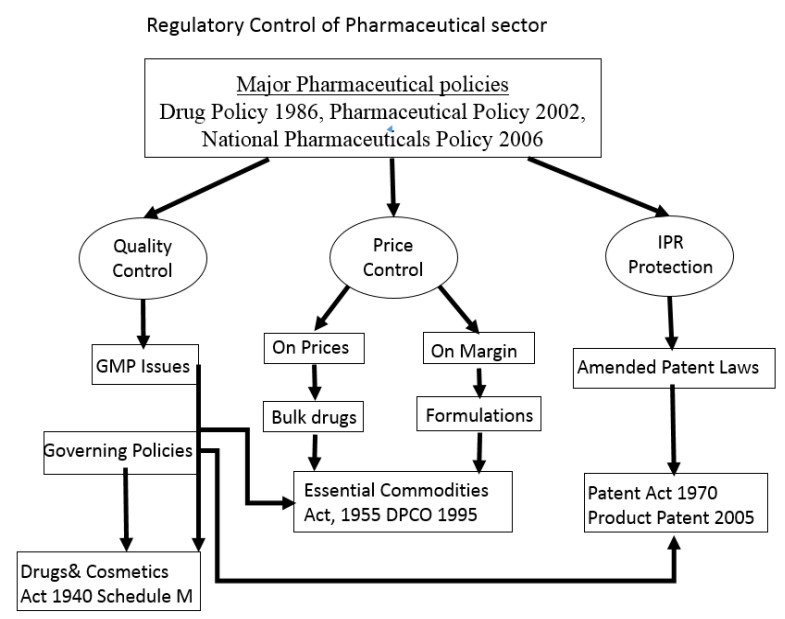

Fig.2. Regulatory Control of Pharmaceutical Policies 


\section{B. Government and UNO ban on drug}

Until January 1986 the Drugs Control Organization which function, as a subordinate office underneath Directorate of Health Services and Director Health Services remained the Ex-Officio Drugs Controller. Thereafter, The Drugs Control Organization developed a self-governing Department with Drugs Controller as Head of Department.

The Drugs Control Department of Delhi State is impressive the requirements of succeeding statutes, accepted by Government of India in Fig. 2:

Drugs \& Cosmetics Act, 1940 and Rules made their underneath.

1. Drugs \& Magic Remedies (Objectionable Advertisements) Act, 1954.

2. Drugs (Prices Control) Order, 2013.

Main accomplishments of the Department in momentary are as under: -

1. Inspection for grant / renewal of licenses to produce allopathic drugs together with whole human blood / blood components / Blood products, surgical dressings, diagnostic reagents/ Kits, disposable syringes/needles/perfusion sets, repacking of drugs, homeopathic medicines, and cosmetics.

2. Analysis for grant / renewal of licenses for retail and wholesale of drugs together with homeopathic medicines. No license for the auction of Ayurveda /Unani / Siddha medicines and cosmetics is compulsory.

3. The assemblage of samples of drugs \& cosmetics from mfg./ sale premises for test / investigation to check their quality being produced and retailed in Delhi.

4. Assessments and raids with an opinion to identify faults under the Act in particular movement and sale of bogus drugs/ cosmetics.

5. Inquiries of cases of infringements under the Act.

6. Assessments of the premises licensed for production and retail of drugs, with an opinion to guarantee that directions of the licenses are complied with.

7. Initiation of tribunals against persons / firms found contravening the provisions of the Act.

8. Under the Act, various advertisements printed in newspapers, periodicals and journals are examined for abhorrent advertisements.

9. Explorations are carried out in all such circumstances where infringements are perceived. Suitable action is taken, and tribunals are launched under the Act in contradiction of the persons originate publishing abhorrent advertisements.

10. Underneath the Order, sales premises are checked to confirm that drugs are retailed at a price not beyond the maximum retail price plus local taxes owed extra. Most people found violating the said
Order are impeached under the Essential Commodities Act, 1955 read with the Drugs (Prices Control) Order, 2013. [18]

Besides, the Drugs Control Department also brings out the following deeds.

1. Advises a new industrialist regarding necessities of premises, location, plant \& machinery,etc. for setting up a factory for the production of drugs/cosmetics.

2. Assigns narcotic drugs to the licensed drugs industrial units.

3. Brings out surveys to discovery out the availability of indispensable drugs in the market and interconnects details of scarcity, if any, to the National Pharmaceutical Pricing Authority, Ministry of Chemicals \& Fertilizers, Govt. of India, every month, for observer up action. [5]

The Central Drugs Standard Control Organization (CDSCO) in India in 2016 has forbidden the manufacture and sale of more than 300 fixed-dose drug combination to avert the abuse of drugs and to avert drug resistance. A gazette notification by Ministry of Health and Family Welfare has banned more than 300 medicines of fixed drug combinations. The Health Ministry banned more than 300 fixed drug combinations over a gazette notice. The ban, which originates into result immediately, follows commendations of an expert committee designed to examine the effectiveness of these drug blends. [3, 9]

\section{Data modeling on Approved and Ban Drugs}

Now knowledge workers have greater challenges to deal with these vast, variety data and information flowing from many direct ions into our repositories. Internet of Things is another wide area, where we have greater and real-time challenges to deal with data from electronic devices, those which could be unstructured or semistructured [22]. This work on the review of knowledge representation models will lead knowledge workers and researchers to choose from these models or to propose newer models to manipulate and process data and information to acquire, extract, represent and codify knowledge. This ultimately leads building KB that can handle bigger data and information for Expert Systems.

Virtually every allopathic drug has the capability to cause some side effects. Drug regulators consider the welfares of a drug against its adverse side effects before approving it. Typically, this endorsement is built on evidence gathered during clinical trials (CTs) on the drug. However, when the drug is permitted and promoted, adverse responses not observed during clinical prosecutions can crop up. This is for the reason that CTs have margins of time, number of subjects, their ethnic/age/health composition, etc. In observation of this, pharmaceutical companies are predictable to monitor, on an enduring basis, the adverse effects experienced by users of their drugs.

Adverse drug reactions (ADRs) are disagreeable events 
which are supposed to have been caused by a drug or medicine. Such ADRs in the real world are conveyed concurrently to health authorities (HA) and the market authorization holders (MAH). These ADRs are then archived by the MAH and HAs. The two foremost databases of such reports are the US FDA's adverse event reporting system (FAERS) and the WHO's 'Vigibase.' The reckoning of such ADRs in these databases is in millions. This kind of an observing activity is occasionally called 'pharmacovigilance'. It is frequently based on voluntary reporting of ADRs by doctors, patients, pharmacists, etc. [4, 19]

\section{Study on Drug based Data Modelling}

The study was made on an idea of iterative method which initially form a database of all drugs promoted in another country, an expert system providing dose prescribed in patients with renal insufficiency and a prototype for documentation of prescriptions in inpatients. Essential elements of a drug demand are a trade name, dosage form, strength, dosage regimen (amount of recommended units and timing of drug administration), and route of administration. While drug databases of promoted drugs contain trade name, dosage form, and forte, they typically do not allocate a unit of recommendation or route of administration to the trade name.

The article also analysis the following model requirements: (1) calculation of prescribed dose for all dosage forms; (2) volume calculation of recommended unit for liquid dosage forms; (3) opportunity to link evidence-founded information to the database to upsurge drug safety and efficiency and to make the most of the specificity of electronic alerts; (4) providing of meaningful default values and drop down lists to facilitate prescribing; and (5) inclusion of all promoted drugs in unique database.

For a prescription-oriented drug database, to allow electronic dose calculation, the relation between the denominator of strength and recommended unit must be available in the coded form. While these are typically identical for most solid, single-dose dosage forms (e.g., tablet), this does not hold true for liquid dosage forms (e.g., strength, $50 \mathrm{mg} / 1 \mathrm{~mL}$; recommended the unit, quantifying spoon)

Therefore, a factor concerning volume or amount included in the unique prescribed unit to the denominator of the asset must be defined, which likewise can be castoff for calculation of the volume of the recommended unit and calculation of the really applied dosage after prompt suspension of an infusion. Short of this factor the recommended dose and volume cannot be calculated. For topical dosage forms like creams, the recommended unit typically cannot be quantified. Accordingly, a factor relating strength and recommended unit cannot be defined, which means that it is not likely to calculate the dosage unless the recommended unit and the included quantity of energetic ingredient can be indicated quantitatively in Fig. 3. [13].

\section{E. Relationship of Generic drugs and its Combination representation}

From the study[23], Predicts ARV drugs consumption for Jugal hospital ARV pharmacy using data mining technique. Result with the data set suggests that tree based modeling approach can effectively be used in predicting the consumption of ARV drugs. By utilizing the KDD process as primary methodology, the study met the prediction process through extraction and preparation of data sets. Finally, the M5P model tree was a better technique for development of prediction method for Jugal hospital ARV pharmacy.

A generic drug is a pharmaceutical drug that is comparable to a brand-name product in dosage, strength, the path of management, quality, performance, and purposeful use. The term may also refer to any drug endorsed under its chemical name without advertising, or to the chemical makeup of a drug slightly than the brand name under which the drug is sold. As per worldwide market tendency, it is predictable that almost $\$ 150$ billion value of drugs will be off patented through the period 2010 to 2017, which will assist as a stage for pharmaceutical companies to improve generic drugs. The pharmaceutical industry in India has exposed a notable growth which in turn has increased the economy of India. [16]

Regarding authorization of pharmaceutical products in the European countries like India is more intricate than in the US, with individually member state taking a knowledgeable authority in accumulation to the European Medicines Agency [EMA], which supervises EU-wide authorization of medicines. The EMA defines a generic medication as a medicine that is developed to be similar to a medication that has previously been authorized (the 'reference medication'). A generic medication comprises the similar active substance(s) as the reference medication, and it is used at the similar dose(s) to treat the same disease(s) as the reference medication. However, the term of the medication, its appearance (such as color or shape) and its wrapping can be disparate from those of the reference medication[1]. Authorization of medication in the EU can be done via three dissimilar routes: The Centralized Procedure [CP], the Decentralized Procedure [DCP] or the Mutual Recognition Procedure [MRP]. Additionally, National Procedures [NP] are in place in specific member states, which sanction a medicine to be authorized by the knowledgeable authority in that specific member state.

The Indian government started heartening more drug developed by Indian companies in the early 1960s, and with the Patents Act in 1970. The Patents Act detached composition patents for foods and drugs were condensed to a retro of five to seven years. The resulting nonexistence of patent protection generated a niche in both the Indian and worldwide markets that Indian companies occupied by reverse- engineering new dealings for manufacturing low-cost drugs. The code of morals issued by the Medical Council of India in 2002 calls for doctor of medicine to recommend drugs by their 
generic names merely.

World Health Organization (WHO) that represents the pharmaceutical product which:

O is typically envisioned to be substitutable with an innovator product,

0 is factory-made without a license from the modernizer company, and

○ is advertised after the expiry date of the patent or other exclusive rights.
There are differing legal requirements in different jurisdictions that define the specifics of what a generic medicine is. However, one and fore most ideologies behind the safe and active use of generic medications is the perception of bioequivalence.[7]

Earlier research has shown a relationship between education level and considerate about generic medicines and exhibits those analysis patients about generics outcomes in greater use of these drugs.

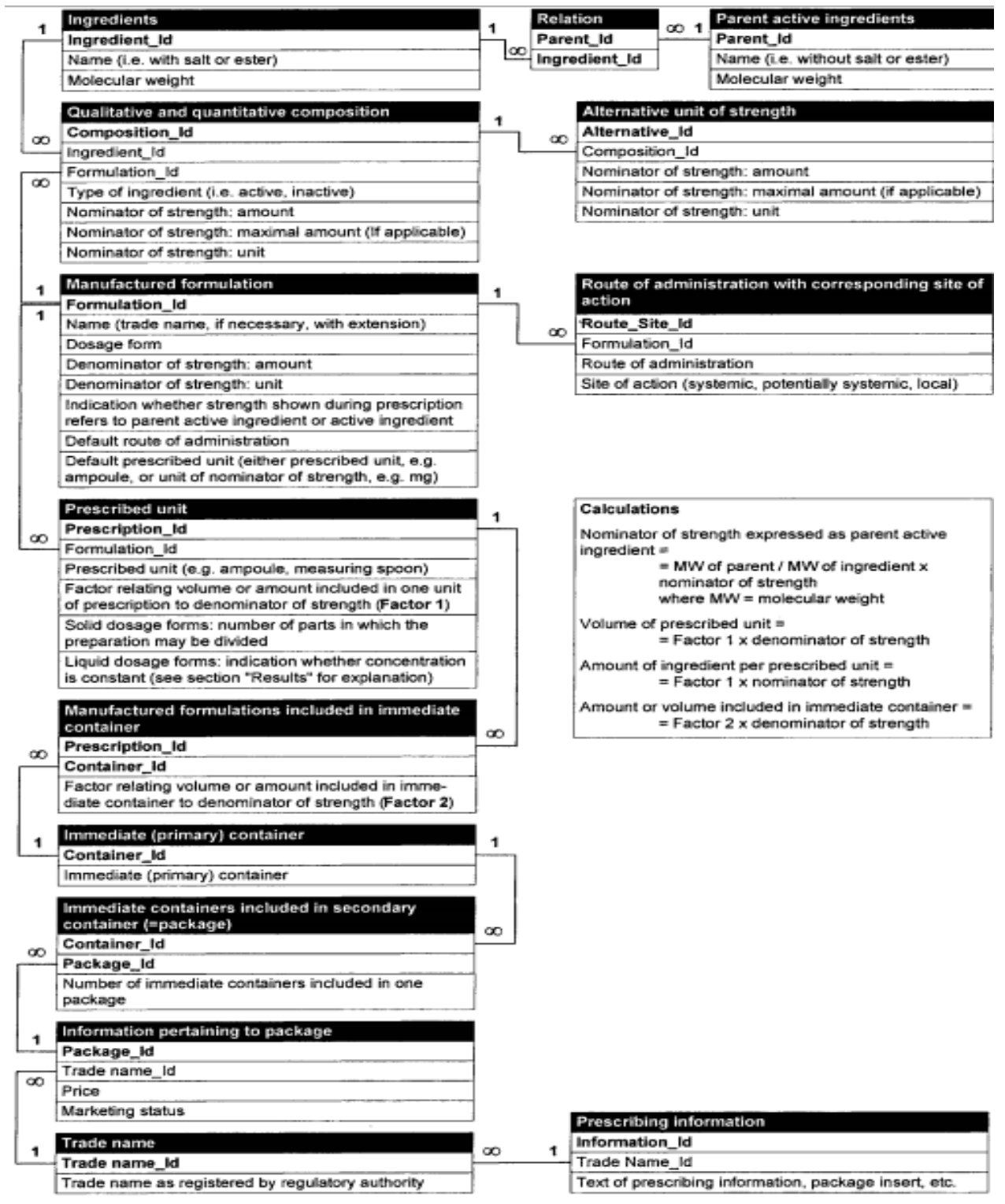

Fig.3. Schematic representation of the drug database model

With limited exemptions, though, the literature has not recognized exact concerns around generics amid older patients. Studies in Germany and Canada have revealed that some patient's deliberate generic drugs, warfarin for instance, chancier to use than brand label drugs

The association among health literateness and views about generic medicines may be connected to patients' understanding of written information on generics, such as generic drug promotions. Patients' capability to direct through healthcare systems and accomplish their chronic health difficulties is roughly related to their health literateness skills. By extension, media campaigns envisioned to promote generic drugs may have a slight impact on generic medicine use except they account for the health literateness levels of the target population. Direct to consumer marketing may also clarify the relationship between health literateness and generic medicine beliefs. 
The difficulty of health literateness and generic medicine beliefs things to see the significant role of the physician in undoubtedly interactive information almost generic drugs with their patients.

Indeed, originate that patients of doctors with deprived communication skills also had additional negative visions on the generic drugs. Because doctors have the essential responsibility for enlightening patients about medicines, those who communicate below par with patients might not share significant information around generic drugs, thus providing a probable explanation for this observed connotation between doctor communication ability and patients' views about generics. Patients with insufficient health literateness have trouble in knowing pronounced as well as inscribed medical information, so they may be particularly inclined to lose important messages about medications from doctors who communicate poorly [10].

Nevertheless, $90 \%$ of the Indian domestic pharmaceutical market, of $1,00,000$ crores and further, comprises drugs retailed below the brand names. There merely not enough generic names equals to the branded medicines retailed. More than 50,000 crores that are half the market and more fixed-dose combinations (FDA) of drugs are partially irrational. Numerous FDC drugs which comprise even eight or nine medicines. To inscribe, and recollect, the constituents of FDC drugs in generic names is unfeasible, since that there would be thousands of FDC products. A blend drug is a fixed-dose combination (FDC) that comprise of two or more active pharmaceutical ingredients (APIs) united in a single dosage form, which is produced and disseminated in fixed doses.

Even if the doctor accomplishes to write a recommendation in generic terms for single-ingredient drugs, pharmacists will vend the brand that maximizes their commission and will in all probability not stock the less costly but comparable product or generic medicine which is good. This overthrows the basic intent of making medicines dose in affordable for customers. Prescription by generic names simply shifts the attention of the pharmaceutical industry's immoral drug elevation to the pharmacist; missing from the prescriber, and resultant in business as usual. Medicines will remain accountable for whatever from $50 \%$ to $80 \%$ of treatment expenses. [8]

The push to generics is lauded by many stakeholders. In global economic environs that is gyratory increasingly antagonistic to the generic drug manufacturer, this is an audacious move, suggestive of the government's categorical support for the few key industries.

Before institutionalizing generics-only policy to the right direction, it is essential to assess and make sure that the Indian generic companies are capable of taking the task. The policy which moves further than rhetoric in different sectors like health, faulty policy design that is affects the country's mortality statistics. $[11,12]$

Indian companies secretarial for the approvals of nearly $40 \%$ in the US financial year ended with the 30 September, and the US Food and Drug Administration (FDA) which permitted a record of 763 generic drugs. First and the primary is the Quality of production. Lately, some of the domestic firms have failed to meet the FDA regulations. Known world over for Quality, Indian firms need to achieve well to give reproducible and trustworthy production consistently from the manufacturing lines to meet the specifications of FDA, keeping economic the cost of production, financing costs, better infrastructure and condensed power and other utility costs, lower taxes and tariffs [16].

According to the report of FDA in Generic Drug Program were approved in the financial year of 2016-17, outstanding with 651 last years, that too was a record. The regulator provides 174 tentative approvals for the year during 2016-17. [20]

\section{PROBLEM DESIGN}

The proposed model constructs a relational model on the individual drugs and the combination generics, which are alive for sales with their trade name and cost. Cost is set to -1 , when the drug and its combination is banned or stopped production, which will support the Physicians or Druggist or Patient to avoid using it. It can be regional wise or country wise or global model to ensure the drug usage for saving an individual life.

The Hypergraph ( $\Psi)$ model is to represent the individual drug, and its combination drugs are considered as hypervertex $(\boldsymbol{v})$, The company which approved to produce the drug with a trade name is considered as $\operatorname{hyperedge}(\xi)$ where their cost is represented as $\operatorname{Weight}(\omega)$. 


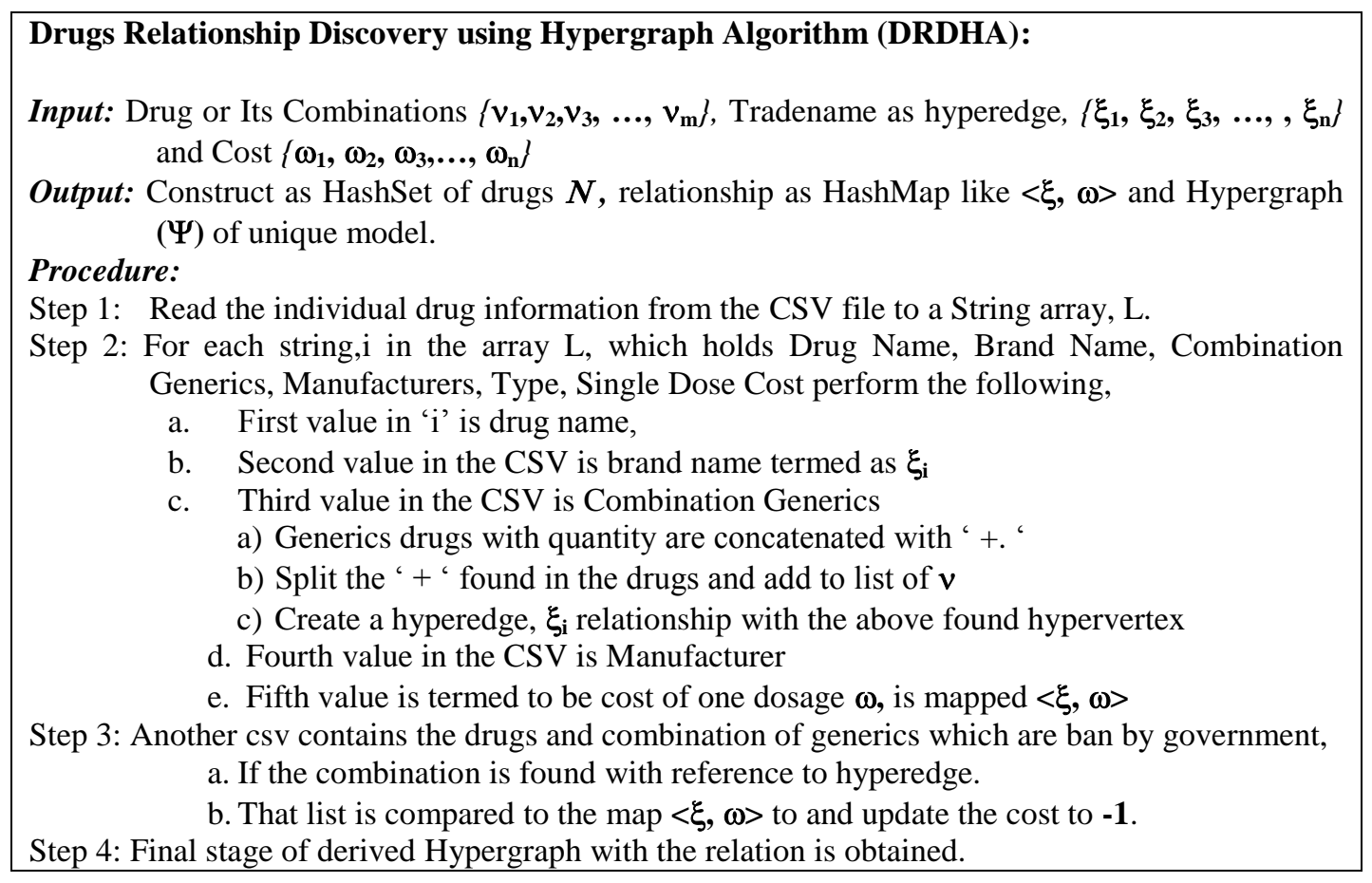

\section{EXPERIMENTAL DESIGN AND RESULT}

The dataset details about the generic medicine list and its price are downloaded from the Government of India's, Bureau of Pharma Public Sector Undertakings of India with The Department of Pharmaceuticals, Ministry of Chemical and Fertilizers. The department website is mentioned here. http://janaushadhi.gov.in/.

The Details of a drug banned and the authorized sales of the brand name of the combination of generic drugs in
India was listed in Central Drugs Standard Control Organization, Director General of Health Services, Ministry of Health and Family Welfare, Government of India website, http://cdsco.nic.in.

Both datasets are not representing the single data model. In this case, testing the generic drugs and combinations for fever and common cold oriented detail is consider as the dataset for the sampling, to construct hypergraph of drugs used and tabulated above in table 1 .

Table 1. List of Drugs and its vertex for fever and common cold used in India

\begin{tabular}{|c|c|c|c|c|c|}
\hline No. of drugs & Category & Drug Name & $\begin{array}{l}\text { No of hyper_edge } \\
\text { has } 1 \text { vertex }\end{array}$ & $\begin{array}{l}\text { No of hyper_edge } \\
\text { has hyper_vertex }\end{array}$ & $\begin{array}{l}\text { No of hyper_edge } \\
\text { banned in India }\end{array}$ \\
\hline 1 & Fever & Acetaminophen & 90 & 9 & 0 \\
\hline 2 & Fever & Aspirin & 87 & 223 & 0 \\
\hline 3 & Fever & Ibuprofen & 138 & 96 & 0 \\
\hline 4 & Fever & Ketoprofen & 17 & 9 & 0 \\
\hline 5 & Fever & Metamizole & 15 & 142 & 157 \\
\hline 6 & Fever & Naproxen & 8 & 9 & 0 \\
\hline 7 & Common Cold & Acrivastine & 0 & 2 & 0 \\
\hline 8 & Common Cold & Codeine & 145 & 0 & 0 \\
\hline 9 & Common Cold & Chlorpheniramine & 37 & 221 & 0 \\
\hline 10 & Common Cold & Guaifenesin & 2 & 661 & 0 \\
\hline 11 & Common Cold & Homatropine & 14 & 11 & 0 \\
\hline 12 & Common Cold & Noscapine & 15 & 1 & 0 \\
\hline 13 & Common Cold & Oxymetazoline & 26 & 3 & 0 \\
\hline 14 & Common Cold & Pseudoephedrine & 5 & 259 & 0 \\
\hline 15 & Common Cold & Triprolidine & 7 & 52 & 0 \\
\hline
\end{tabular}

\section{A. Construction of hypergraph}

Based on the above dataset on drug and its combination are medically termed as generic drugs and
Combination of generic drugs. Each generic drugs have single vertex and whereas the combination of generic drugs is an association of more than one generic drugs. 
Table 2. Sample data for drug 'Naproxen' based generic medicine and its combination brand details

\begin{tabular}{|c|c|c|c|c|}
\hline Drug Name & Brand Name & Combination Generics & Manufacturers & Type \\
\hline Naproxen & Artagen & & Ranbaxy & Tablet \\
\hline Naproxen & Movibon & & Brown \& Burk Pharmaceutical & Tablet \\
\hline Naproxen & Movibon (250mg) & & Micro B \& B & Tablet \\
\hline Naproxen & Naprosyn & & RPG Life Sciences & Capsule/ Tablet \\
\hline Naproxen & Naprosyn & & Elder Pharmaceuticals & $\begin{array}{c}\text { Modified Release } \\
\text { Capsule/ Tablet }\end{array}$ \\
\hline Naproxen & Xenar - Cr & & Shreya (Rallis India) & Capsule/ Tablet \\
\hline Naproxen & Xenobid & & Shreya (Rallis India) & $\begin{array}{c}\text { Cream/ Gel/ } \\
\text { Ointment }\end{array}$ \\
\hline Naproxen & Xenobid Gel & & Crescent Therapeutics Ltd. & Capsule/ Tablet \\
\hline Naproxen & Arthopan & Naproxen, Pantoprazole & Capsule/ Tablet \\
\hline Naproxen & Arthopan (500+20) & Naproxen, Pantoprazole & Crescent Therapeutics Ltd. & Capsule/ Tablet \\
\hline Naproxen & Naprodom (250+10) & Naproxen, Domperidone & Crescent Therapeutics Ltd. & Capses \\
\hline Naproxen & Naprodom (500+10) & Naproxen, Domperidone & Crescent Therapeutics Ltd. & Capsule/ Tablet \\
\hline Naproxen & Naxdom 250 & Naproxen, Domperidone & Sun Biotic Labs. & Capsule/ Tablet \\
\hline Naproxen & Naxdom 500 & Naproxen, Domperidone & Sun Biotic Labs. & Capsule/ Tablet \\
\hline Naproxen & Pacinac -NP & Naproxen, Domperidone & Gentech Healthcare Pvt Ltd & Capsule/ Tablet \\
\hline Naproxen & $\begin{array}{c}\text { Xenadom (250mg/ } \\
10 m g)\end{array}$ & $\begin{array}{c}\text { Naproxen 250mg + } \\
\text { Domperidone 10mg }\end{array}$ & Mesmer (Icon) & Capsule/ Tablet \\
\hline Naproxen & $\begin{array}{c}\text { Xenadom (500mg/ } \\
10 m g)\end{array}$ & $\begin{array}{c}\text { Naproxen 500mg + } \\
\text { Domperidone 10mg }\end{array}$ & Mesmer (Icon) & Capsule/ Tablet \\
\hline
\end{tabular}

For example, a sample dataset of Naproxen is shown in table 2, It contains 8 generic and 9 combination generic drugs. Using the dataset details based on table 1, the following table 3 is constructed step by step, to denote the number of hyperedges and its relationship among the vertex. $1,2,3, \ldots 15$ are the sample details given below along with the notification flag indicates the banned medicine in India.

Based on the above table 3, the graph of the following Fig. 4 highlights the comparison of vertex and hypervertex found among the 15 drugs.

Table 3. Time taken for the construction of Hypergraph found in Table 3

\begin{tabular}{|c|c|c|c|}
\hline No. of drugs & $\begin{array}{c}\text { No of hyperedge } \\
\text { has 1 vertex }\end{array}$ & $\begin{array}{c}\text { No of hyperedge has } \\
\text { hypervertex }\end{array}$ & $\begin{array}{c}\text { No of hyperedge } \\
\text { banned in India }\end{array}$ \\
\hline $\mathbf{1}$ & 90 & 9 & 0 \\
\hline $\mathbf{2}$ & 177 & 232 & 0 \\
\hline $\mathbf{3}$ & 315 & 328 & 0 \\
\hline $\mathbf{4}$ & 332 & 337 & -157 \\
\hline $\mathbf{5}$ & 347 & 479 & -157 \\
\hline $\mathbf{6}$ & 355 & 488 & -157 \\
\hline $\mathbf{7}$ & 355 & 490 & -157 \\
\hline $\mathbf{8}$ & 500 & 490 & -157 \\
\hline $\mathbf{9}$ & 537 & 711 & -157 \\
\hline $\mathbf{1 0}$ & 539 & 1372 & -157 \\
\hline $\mathbf{1 1}$ & 553 & 1383 & -157 \\
\hline $\mathbf{1 2}$ & 568 & 1384 & -157 \\
\hline $\mathbf{1 3}$ & 594 & 1387 & -157 \\
\hline $\mathbf{1 4}$ & 599 & 1646 & -157 \\
\hline $\mathbf{1 5}$ & 606 & 1698 & \\
\hline
\end{tabular}




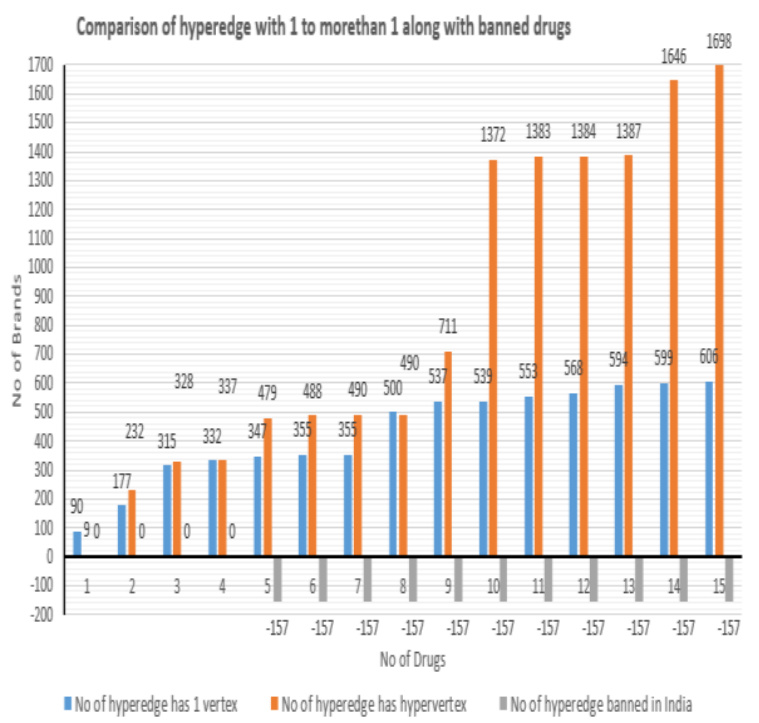

Fig.4. Comparison over the identification of hyperedge based on Table 1

\section{B. Time taken for hypergraph}

Based on the table 1, hypergraph was constructed and their details were shown in table 3 . Time take to identify the relationship among the drugs were shown in table 4 and its pictorial representation of the table is given in the below Fig. 5.

Table 4. Details of Relationship identified among the drugs

\begin{tabular}{|c|c|c|}
\hline $\begin{array}{c}\text { No. of } \\
\text { drugs }\end{array}$ & $\begin{array}{c}\text { Time taken to construct } \\
\text { Hyper Edge with 1 } \\
\text { vertex (milliseconds) }\end{array}$ & $\begin{array}{c}\text { Time taken to construct } \\
\text { Hyper Edge with more than } \\
\text { 1 vertex (milliseconds) }\end{array}$ \\
\hline 1 & 720 & 72 \\
\hline 2 & 1326 & 1847 \\
\hline 3 & 2343 & 2392 \\
\hline 4 & 2341 & 2368 \\
\hline 5 & 2444 & 3495 \\
\hline 6 & 2493 & 3425 \\
\hline 7 & 2485 & 3432 \\
\hline 8 & 3645 & 3430 \\
\hline 9 & 3796 & 5198 \\
\hline 10 & 3775 & 10265 \\
\hline 11 & 3885 & 9692 \\
\hline 12 & 3991 & 9689 \\
\hline 13 & 4184 & 9712 \\
\hline 14 & 4198 & 11781 \\
\hline 15 & 4249 & 11938 \\
\hline
\end{tabular}

Based on the above Fig. 5 can identify the minimal time to construct the relationship among the drugs depends on the number of combinatorics of generic drugs.

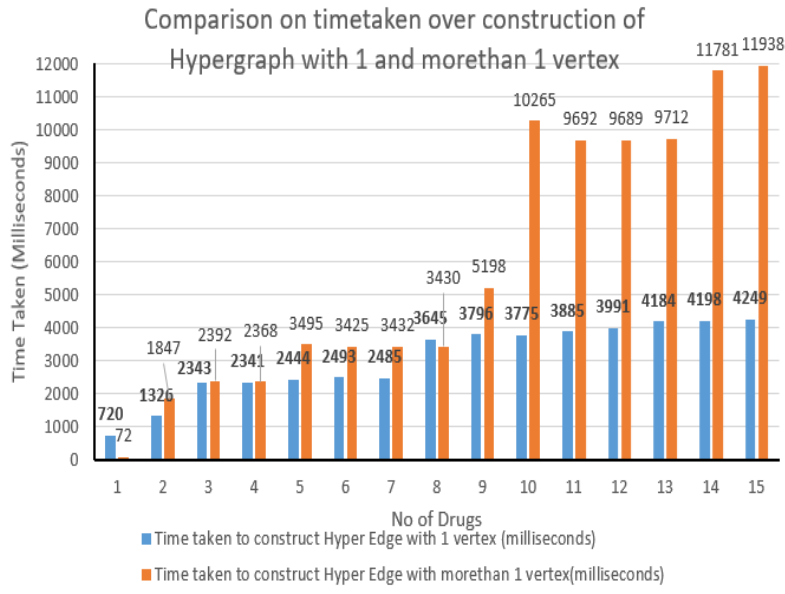

Fig.5. Comparison over time taken to identify the relationship based on Table 1

\section{CONCLUSION AND FUTURE WORKS}

This proposed work of construction of a hypergraph to identify the relationship among the generic drugs and its combinations was performed among the various common parameters like fever and the common cold in India. Implementation was performed among 15-drug to produce a hypergraph, which in turn was able to predict brands around 606 generic drugs and 1698 combination of drugs termed as hypervertex, among the complete 157 banned drugs in India. Drugs relationship was predictable, their price for single dose is represented as the weight of hyperedge and banned medicine is represented as -1 .

In the future work, will help to find availability of drugs based on spatial database; where it can provide regional wise available medicines, and the next level of work will be to detect generic drugs and its combination based on symptoms of the patient.

\section{REFERENCES}

[1] Amani Naser Tahat, Maurice HT Ling, "Mapping Relational Operations onto Hypergraph Model", The Python Papers volume 6, Issue 1, pp: 4, 2017, arXiv: 1105.6118 [cs.DB].

[2] BekaErgemlidze, Ervin Győri, Abhishek Methuku, "Asymptotics for Tur'an numbers of cycles in 3-uniform linear hypergraphs, 2017, arXiv preprint arXiv:1705.03561, doi:10.1016/j.endm.2017.06.064.

[3] Ministry of Health and Family Welfare of India online portal for National Health as Digital Initiatives, 2017, https://www.nhp.gov.in/

[4] SamadhanGhubade, Krishna Asvalayan, SharayuParanjpe, Kushagra Gupta and Anil Gore, "On shapes of ADR report accumulation data banned drugs", Current Science, Volume 113, Issue 9, 10, pp. 1664-1667, 2017, doi:10.18520/cs/v113/i09/1664-1667. 
[5] Drugs Control Department under Directorate of Health Services of India Portal, 2017, http://delhi.gov.in/wps/wcm/

[6] JinalPatel, "Different Data Structures Used for Playing with Anagram", International Journal of Advance Engineering and Research Development, Volume 2, Issue 5, pp 243-249, 2015, doi:10.21090/ijaerd.020533.

[7] Suzanne Dunne, Bill Shannon, Colum Dunne and Walter Cullen, "A review of the differences and similarities between generic drugs and their originator counterparts, including economic benefits associated with usage of generic medicines, using Ireland as a case study", BMC PharmacolToxicol, Volume 14 Issue 1, pp.1-19, 2013, doi:10.1186/2050-6511-14-1.

[8] Jessy Shaji and Shital Lodha, "Regulatory Status of Banned Drugs in India", Indian Journal of Pharmaceutical Education and Research, Volume 44 Issue 1, pp. 86-94, 2010.

[9] Manjari Gupta, Anil Ghom, FM debta, Sunil Vyas, Abhijeet Deoghare, Prashant Gupta, Shantala Gupta, "Banned Drugs: still available in India", Journal of Indian Academy of Oral Medicine and Radiology, Volume 23 Issue 3, pp. S380-381, 2010, doi:10.5005/jp-journals10011-1174.

[10] Alice Iosifescu, Ethan A. Halm, Thomas McGinn, Albert L. Siu, and Alex D. Federman, "Beliefs about generic drugs among elderly adults in hospital based primary care practices", Patient EducCouns Volume 73 Issue 2, pp. 377-383, 2008, doi:10.1016/j.pec.2008.07.012.

[11] Gautam CS, Aditya S, "Irrational drug combinations: need to sensitize under graduate", Indian Journal Pharmacol, Volume 38, Issue 3, pp.169-70, 2006.

[12] Tiwary P., Rajshree, "Role of medicine information in promoting rational drug use", Pharma Times, Volume 38, Issue 7 pp.1-20, 2006.

[13] Peter Martin, Walter E. Haefeli, Meret Martin-Facklam, "A Drug Database Model as a Central Element for Computer Supported Dose Adjustment within a CPOE System", Journal of the American Medical Informatics Association, volume 11, Issue 5, pp. 427-432, 2004.

[14] David A. Papa, Igor L. Markov, "Hypergraph Partitioning and Clustering", Handbook of Approximation Algorithms and Metaheuristics, pp. 1- 38, 2004, DOI: 10.1201/9781420010749.ch61.

[15] E.-H. Han, G. Karypis, V. Kumar and B. Mobasher, "Hypergraph Based Clustering in High Dimensional Data Sets: A Summary of Results," IEEE Bulletin of Technical Committee on Data Engineering, Volume 21 Issue 1, pp. 15-22, 1998.

[16] S Sravika, R Bhavana, V Sharmila, S Anusha, NVN Mounica, D Nagarjuna Reddy and MV Nagabhushanam, "A comprehensive study on regulatory requirements for development and filing of generic drugs globally", The Pharma Innovation Journal 2017, Volume 6, Issue 4, pp.153-158, 2017.

[17] Ketaki D. Patil, "Indian Pharma Industry in Global Context: A Statistical Overview", International Journal of Institutional Pharmacy and Life Sciences, Volume 7, Issue3, p 22-28, 2017.

[18] Varsha Galani," Choice of Better Medicine in India: Branded Vs Generic Medicine”, Volume 5, Issue 3, pp 1-2, 2017.

[19] Wei Dua,e, Sallie-Anne Pearson, Nicholas A Buckley, Cathy Daya, Emily Banks, "Diagnosis-based and external cause-based criteria to identify adverse drug reactions in hospital ICD-coded data: application to an Australian population-based study", Public Health Research \&
Practice, Volume 27, Issue 2, e2721716, 2017, doi: http://dx.doi.org/10.17061/phrp2721716.

[20] LiveMint E-Paper on "Generic drug approvals in US hit record high in FY17", http://www.livemint.com, 2017.

[21] Sandhya V. Kawale, S. M. Kamalapur, "Image Retrieval using Hypergraph of Visual Concepts", International Journal of Information Technology and Computer Science(IJITCS), Vol.9, No.12, pp.38-44, 2017. DOI: 10.5815/ijitcs.2017.12.05

[22] Hepsiba Mabel V, Justus Selwyn,"A Review on the Knowledge Representation Models and its Implications", International Journal of Information Technology and Computer Science(IJITCS), Vol.8, No.10, pp.72-81, 2016. DOI: $10.5815 /$ ijitcs.2016.10.09

[23] Patrick D. Cerna, Thomas Jemal Abdulahi,"Prediction of Anti-Retroviral Drug Consumption for HIV Patient in Hospital Pharmacy using Data Mining Technique", International Journal of Information Technology and Computer Science(IJITCS), Vol.8, No.2, pp.52-59, 2016. DOI: $10.5815 /$ ijitcs.2016.02.07

\section{Authors' Profiles}

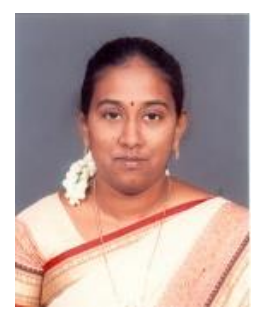

Shalini $\mathbf{R}$ is a Research Scholar in the Department of Computer Science and Engineering in National Institute of Technology, Tiruchirappalli (NITT), India. She finished her M.E. (CSE) from Government College of Technology, Coimbatore, Tamil Nadu, India. Her research areas include High-performance computing and Graph Theory.

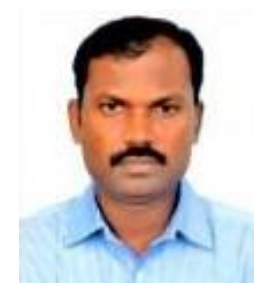

Mohan $\mathbf{R}$ is currently an Assistant Professor in the Department of Computer Science and Engineering department in National Institute of Technology, Tiruchirappalli (NITT), India. He finished his M.E (Software Engineering) from Jadavpur University, Kolkata, India. He received his Ph.D. degree from National Institute of Technology, Tiruchirappalli (NITT), India. His research area includes High-performance computing, Graph theory, Image processing and Wireless networks.

How to cite this paper: Shalini R, Mohan R, "Drugs Relationship Discovery using Hypergraph", International Journal of Information Technology and Computer Science(IJITCS), Vol.10, No.6, pp.54-63, 2018. DOI: 10.5815/ijitcs.2018.06.06 